\title{
Cyclone surface pressure fields and frontogenesis from NASA scatterometer (NSCAT) winds
}

\author{
David F. Zierden, Mark A. Bourassa, and James J. O'Brien \\ Center for Ocean-Atmospheric Prediction Studies, Florida State University, Tallahassee, 32306-2840
}

\begin{abstract}
Two extratropical marine cyclones and their associated frontal features are examined by computing surface pressure fields from NASA scatterometer (NSCAT) winds. A variational method solves for a new surface pressure field by blending highresolution $(25 \mathrm{~km})$ relative vorticity computed along the satellite track with an initial geostrophic vorticity field. Employing this method with each successive pass of the satellite over the study area allows this surface pressure field to evolve as dictated by the relative vorticity patterns computed from NSCAT winds. The result is a high-resolution surface pressure field that captures features such as fronts and low-pressure centers in more detail than National Centers for Environmental Prediction (NCEP) reanalyses. While using the actual relative vorticity to adjust the geostrophic vorticity ignores the ageostrophy of surface winds, which can be significant in the vicinity of fronts and jet streaks, it is a necessary approximation given that the technique uses only surface data. The NSCAT surface pressure fields prove to be nearly as accurate as NCEP reanalyses when compared to ship and buoy observations, which is an encouraging result given that NCEP reanalyses incorporate a myriad of data sources and the NSCAT fields rely primarily on one source. In addition, the high-resolution relative vorticity fields computed from NSCAT winds reveal the location of surface fronts in great detail. These fronts are verified using NCEP analyses, in situ data, and satellite imagery.
\end{abstract}

\section{Introduction}

The lack of conventional data over the oceans has long been a limiting factor in the accuracy of weather forecasting [Atlas et $a l ., 1985]$. Often, the only data available are surface observations from ships and buoys, which are sparse outside shipping lanes and the Tropical Ocean-Global Atmosphere experiment (TOGA)-Tropical Atmosphere-Ocean (TAO) buoy array. Conventional data are now supplemented with satellite data, and the challenge lies in finding methods to utilize these new data sources best. One such source is surface wind vector measurements form spaceborne scatterometers, which can be used to derive surface pressure fields.

NASA scatterometer (NSCAT) and other scatterometers provided wind measurements over the ocean with much greater resolution and coverage than were previously available. Recent research looked to find ways to utilize this high-quality data source. A common approach was to form gridded products [Liu et al., 1998; Bourassa et al., 1999; Verschell et al., 1999]. These gridded products were used to drive ocean circulation models, to improve surface fluxes for general circulation models, and to study the evolution of regional winds.

The assimilation of scatterometer winds has also had a positive impact on numerical weather prediction (NWP). Early impact studies [Baker et al., 1984, Duffy et al., 1984] using Seasat-A winds improved surface analyses significantly, but had limited effects on higher levels and forecasts. Duffy and Atlas [1986] first demonstrated improved forecasts with the vertical extension of Seasat-A surface winds, which adjusted mass at higher levels of the model, not just the surface. Later,

Copyright 2000 by the American Geophysical Union.

Paper number $2000 \mathrm{JC} 900062$.

$0148-0227 / 00 / 2000 \mathrm{JC} 900062 \$ 09.00$ the assimilation of ERS-1 winds into the European Centre for Medium-Range Weather Prediction (ECMWF) model impacted the forecasts only marginally [Hoffman, 1993]. Andrews and Bell [1998] demonstrated marked improvements in the United Kingdom Meteorological Office forecasts by assimilating ERS-1 winds, particularly over the Southern Ocean where conventional data are sparse. More recently, Atlas and Hoffman [2000] found that the greatest positive impacts of NSCAT winds on NWP forecasts resulted from the vertical extension of surface winds and the modification of surface pressure fields.

Some studies have employed scatterometer winds in diagnostic studies of midlatitude and tropical cyclones. In many of these studies, scatterometers were only one of many data sources implemented in improving NWP analyses of the feature [Anthes et al., 1983; Tomassini et al., 1998; Liu et al., 1998]. In contrast, Harlan and O'Brien [1986] assimilated only Seasat-A scatterometer data with National Centers for Environmental Prediction (NCEP, formerly NMC) surface pressure fields to obtain an improved estimate of the central pressure in the QE-II storm of 1978. All of these studies showed how scatterometer winds improved estimates of the central surface pressures and predicted intensities of the systems.

Brown and Zeng [1994] developed a method for computing surface pressure fields in midlatitude cyclones using ERS-1 winds from a single swath and a boundary layer model. Surface gradient winds were found using ERS-1 wind data as input to the boundary layer model. Surface pressures were then computed from the gradient winds, and a reference pressure was located within the field. The computed surface pressure fields distinguished fronts and located the centers of cyclones accurately while giving improved estimates of central pressure over NCEP analyses. Hsu and Wurtele [1997] employed this method with Seasat-A winds in a similar study. The strength of the 


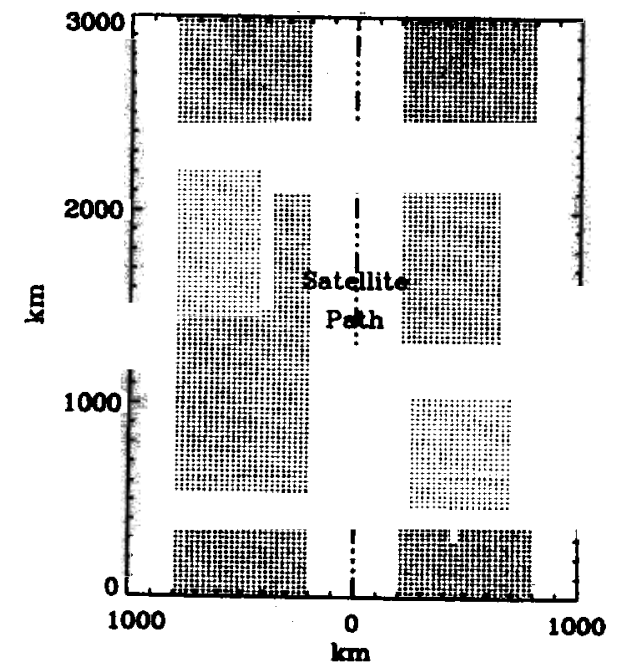

Figure 1. Data coverage and resolution along the path of the ADEOS. Dots mark the relative location of each wind sample.

boundary layer approach was twofold: (1) the surface pressure field was derived almost exclusively from scatterometer data, and (2) swath data were used directly, without averaging in space or time. The drawback was that pressures could only be computed within the swath of wind data. A discussion of the accuracy of scatterometer surface pressure fields is given by Zeng and Brown [1998]. These surface pressure fields showed greatest improvement over NWP analyses over the Southern Hemisphere, where the lack of conventional observations can cause entire systems to be misplaced or missed all together [Brown and Levy, 1986; Levy and Brown, 1991].

This study makes use of the high-quality NSCAT wind data by deducing surface pressure fields through the use of a variational method. The primary goals are (1) to use NSCAT winds to determine surface pressure fields, (2) to follow the evolution of surface features described mostly with NSCAT data, (3) to locate and identify surface fronts, and (4) to provide a surface pressure field that could be used to improve NWP over the oceans.

Section 2 describes the data sets, including specifics of NSCAT and its near-surface wind observations. Section 3 details the variational method used to determine surface pressures. The variational method involves the assimilation of relative vorticity computed from the NSCAT wind vectors. Surface fronts are located and identified in the relative vorticity field as localized bands of high relative vorticity (section 3.1.1). These features are verified as fronts using in situ observations and visible GOES 9 imagery. Section 4 uses NSCAT surface pressure fields to follow a case of cyclogenesis and a case of frontogenesis in the North Pacific. Results show that the NSCAT surface pressure fields resolve the structure of these features in more detail than the NCEP reanalyses. The NSCAT pressure fields also agree better with NSCAT winds as far as the location of cyclone centers and the orientation of horizontal pressure gradients are concerned. Quantitatively, the NSCAT pressure fields compare well with NCEP, especially near the reference buoys and where recent satellite data are available.

\section{Data}

\subsection{NSCAT}

The primary data used in this study are the NSCAT2 level II winds with a resolution of $25 \mathrm{~km}$ along the satellite's path. These winds are an updated version processed by the Jet Propulsion Laboratory from measured backscatter using an improved model function. NSCAT operated aboard Japan's ADEOS for 9 months from late September 1996 through June 1997. NSCAT was the first of a new generation of scatterometers; it used many technological advances to improve the quality, coverage, and resolution of near-surface winds. NSCAT's radar operated in $\mathrm{Ku}$ band $(13.995 \mathrm{GHz})$ rather than the $\mathrm{C}$ band as was done by ERS- 1 . This frequency led to greater accuracy at low wind speeds $\left(<4 \mathrm{~m} \mathrm{~s}^{-1}\right)$, although sensitivity to attenuation by liquid water was increased. Engineering advancements in the sensors increased the signal to noise ratio of the backscatter measurements, greatly improving ambiguity selection. In addition, each wind cell was viewed from three different angles. The NSCAT radar was dualpolarized from one antenna, providing additional measurements to aid in the ambiguity selection. NSCAT was equipped to measure backscatter on both sides of the satellite track, doubling the coverage of ERS-1, which viewed only on one side.

A digital Doppler filter grouped overlapping backscatter measurements from the different viewing angles into $25 \mathrm{~km}$ by $25 \mathrm{~km}$ cells. The wind speed and direction were computed for each cell using the observed backscatters and a lookup table. Calibration/validation of the NSCAT model function was more accurate than previous scatterometers because of comparisons with high-quality in situ surface observations from research vessels [Bourassa et al., 1997], National Data Buoy Center (NDBC) buoys [Freilich and Dunbar, 1999], and the TOGATAO array (K. Kelley and S. Dickenson, personal communication, 1998). In particular, these in situ data included many observations at low and high wind speeds, enabling accurate calibration/validation and removing the low wind speed biases found in other scatterometers.

Attenuation by liquid in the atmosphere, particularly heavy precipitation, is a disadvantage of the $\mathrm{Ku}$ band frequency. Contamination from precipitation droplets can significantly degrade the quality of scatterometer-computed wind vectors. Ideally, inclusion of a passive microwave radiometer on the satellite platform could have identified contaminated cells and flagged them appropriately. Unfortunately, mission specifications and funding did not allow for such an instrument to be included with NSCAT, so it is difficult to identify contaminated cells. Studies are ongoing to determine the effects of precipitation on the overall accuracy of the NSCAT winds.

The ADEOS was a low-altitude, Sun synchronous, nearpolar orbiter. In this orbit, NSCAT covered $90 \%$ of the ice-free ocean every 2 days. The antenna configuration allowed winds to be measured in $600 \mathrm{~km}$ wide swaths on each side of the satellite, with a $400 \mathrm{~km}$ gap in the nadir view between the swaths (Figure 1). NSCAT2 level II wind data covered swaths on each side of the satellite, with each swath 24 cells wide. These rows of 24 cells were perpendicular to the satellite's path (Figure 1).

NSCAT proved to be a very reliable instrument, determining near-surface winds (calibrated to a height of $10 \mathrm{~m}$ ) more accurately and with fewer aliases than previous scatterometers. In the open ocean the chances of selecting an incorrect ambi- 
guity were negligible at wind speeds over $8 \mathrm{~m} \mathrm{~s}^{-1}$ [Bourasse et al., 1997]. Below that threshold the chances of incorrect ambiguity selection increased with decreasing wind speed. The RMS difference between NSCAT and research vessel winds was found to be $1.6 \mathrm{~m} \mathrm{~s}^{-1}$ for wind speed (for wind speeds $>4$ $\mathrm{m} \mathrm{s}^{-1}$ ) and $13^{\circ}$ for direction. They found no statistically significant biases at low or high wind speeds. Freilich and Dunbar [1999] supported these findings in a comparison to qualitycontrolled NDBC buoy observations.

\subsection{NCEP Reanalyses and NDBC Buoys}

NCEP reanalysis mean sea level pressures are used to initialize the pressure field and to update boundary conditions. The NCEP mean sea level field is different from its surface pressure field, primarily over elevated land surfaces and because of small variations due to the limited spectral resolution of the model. The NCEP mean sea level pressure field is the most accurate representation of surface pressures over the ocean. Throughout the remainder of the text, the term "surface pressure" will apply to all pressure values, including the NCEP reanalysis mean sea level pressure product. The NCEP mean sea level pressure data are available on a $2.5^{\circ}$ global grid at 6 hour intervals. A third data source is in situ surface pressures from NDBC buoys 46003 , located at latitude $51^{\circ} 51^{\prime} 5$ 'N and longitude $20^{\circ} 5^{\prime} 3^{\prime \prime} \mathrm{E}$, and 51001 , located at latitude $23^{\circ} 24^{\prime} 4^{\prime \prime} \mathrm{N}$ and longitude $197^{\circ} 34^{\prime} 1^{\prime \prime} \mathrm{E}$.

\section{Methodology}

\subsection{Method and Study Area}

A goal of this study is to devise a technique of deriving surface pressure fields from NSCAT winds, which have greater coverage and better resolution than ERS-1 winds. Like Brown and Zeng [1994], individual swath data are used, preserving the spatial resolution and small-scale features present in NSCAT winds. Unlike Brown and Zeng [1994], any data within the domain has an influence on the entire pressure field. Also, the surface pressure field will evolve in time with each satellite pass over the domain.

The study area is the North Pacific Ocean between $20^{\circ}$ and $55^{\circ} \mathrm{N}$ latitude and between $165^{\circ}$ and $225^{\circ} \mathrm{E}$ longitude. It is largely free of land and ice (scatterometers only work over water) and large enough to capture synoptic-scale systems. Midlatitude cyclones track through the region. Furthermore, conventional data are sparse, and numerical weather prediction analyses can use improvement in this area. The study area could expect to see three to four passes of the satellite in the ascending node and another three to four passes in the descending node each day (Figure 2). All computations and analyses are performed on a $0.25^{\circ}$ grid over the domain, preserving the small-scale features present in the high-resolution NSCAT winds.

The technique developed in this study builds on the strengths of Brown and Zeng [1994] and incorporates the variational method of Hartan and O'Brien [1986]. The procedure (Plate 1) begins with an NCEP mean surface pressure field and interpolates it onto the $0.25^{\circ}$ grid over the domain. For each subsequent pass of the satellite over the study area the two swaths of NSCAT wind data are assimilated into the pressure field. Although surface pressure and winds are physically different data types, they are related through vorticity. Relative vorticity is computed in the swaths from NSCAT winds and then interpolated to the $0.25^{\circ}$ domain grid, while geostrophic

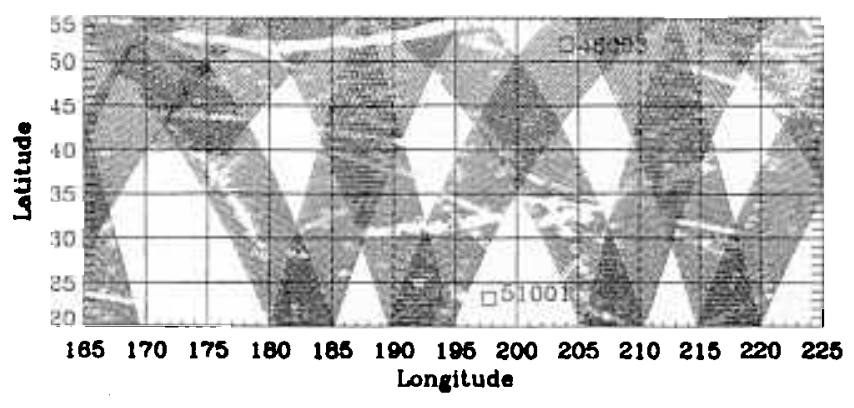

Figure 2. Typical daily coverage of NSCAT winds over the study area. Gaps within the swaths indicate missing data. National Climate Data Center (NCDC) buoy locations are marked with a square.

vorticity is computed from the pressure field. A variational method solves for a new geostrophic stream function, minimizing the difference between the new geostrophic vorticity and the old geostrophic vorticity where satellite data are present and minimizing the difference between the new geostrophic vorticity and the old geostrophic vorticity where no satellite data are present. The result is an updated surface pressure field that captures the features found in the NSCAT vorticity. The treatment of NSCAT relative vorticity as geostrophic ignores the ageostrophy of surface winds, which can be significant in the vicinity of fronts and jet streaks. However, this approximation is necessary in the absence of upper air thermal and mass fields. Repeating the procedure with each new pass of the satellite over the domain allows the field to evolve in time as dictated by NSCAT data. The steps of this procedure are described in detail in sections 3.2-3.6.

\subsection{Computing Relative Vorticity}

NSCAT winds are of high spatial density and are located on a regular grid aligned with the satellite path; consequently, relative vorticity is easily computed using centered finite differences. The speed and arimuthal direction of the winds are converted to across-track $\left(u^{\prime}\right)$ and along-track $\left(v^{\prime}\right)$ components in a coordinate system aligned with the satellite track. The relative vorticity $\zeta$, at each interior point in the two swaths is

$$
\zeta=\left(v_{i+1, j}^{\prime}-v_{i-1, j}^{\prime}\right) / \Delta x^{\prime}-\left(u_{i, j+1}^{\prime}-u_{i, j-1}^{\prime}\right) / \Delta y^{\prime},
$$

where $i$ denotes cell position across the swath, $j$ denotes cell position along the swath, and $x^{\prime}$ and $y^{\prime}$ are across-track and along-track locations. $\Delta x^{\prime}$ and $\Delta y^{\prime}$ are twice the cell size and are computed directly from the latitude and longitude of the corresponding data points instead of being held constant at 50 $\mathrm{km}$. They varied between 49 and $51 \mathrm{~km}$. If wind data are missing at any of the neighboring cells, the relative vorticity at that point is considered missing. Delunay triangulation and interpolation [Renka, 1982] then transfers the satellite relative vorticity onto the $0.25^{\circ}$ grid.

The RMS difference in NSCAT wind speeds is $\sim 1.6 \mathrm{~m} \mathrm{~s}^{-1}$ when compared to in situ data [Bourassa et al., 1997; Freilich and Dunbar, 1999]. This uncertainty propagates through relative vorticity calculations and results in an uncertainty in relative vorticity values of roughly $1 \times 10^{-4} \mathrm{~s}^{-1}$, similar in magnitude to maximum values in strong synoptic-scale systems. However, this RMS uncertainty in NSCAT wind speeds includes both systematic biases and random errors in the 


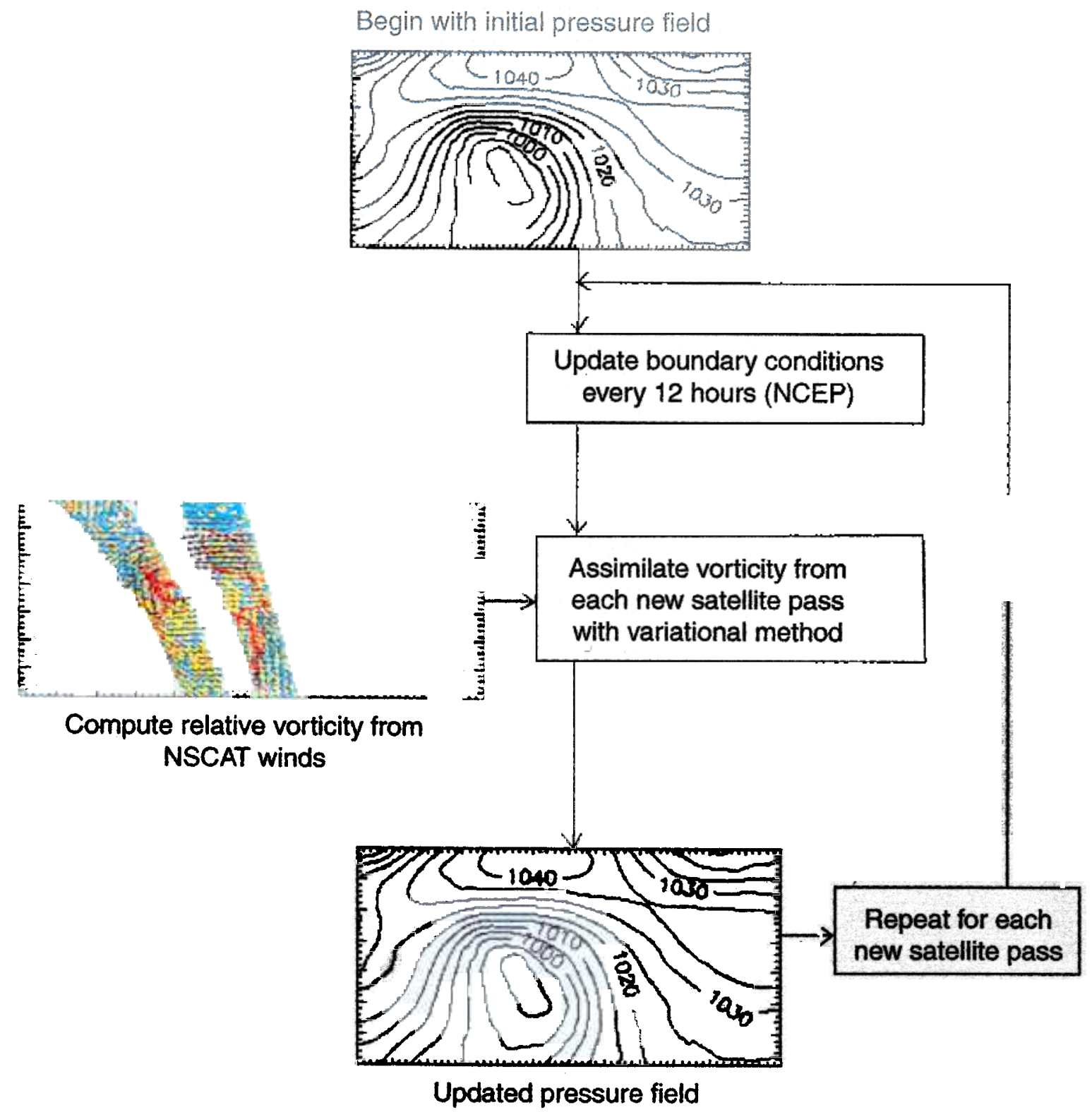

Plate Methodology of computing surface pressure fields from NSCAT winds.

NSCAT winds and the in situ data. Since relative vorticity involves the difference in $u$ and $v$ components, most of the uncertainty in relative vorticity is due to random error alone in the NSCAT winds. The consistency of NSCAT relative vorticity fields with surface features and NCEP geostrophic vorticity suggests that the uncertainty in the NSCAT relative vorticity is small $\left(<1 \times 10^{-5} \mathrm{~s}^{-1}\right)$ and that random errors in the NSCAT winds are $<0.7 \mathrm{~m} \mathrm{~s}^{-1}$.

\subsection{Frontal Detection}

A secondary result of this study deals with the strong signature of surface fronts in the relative vorticity fields computed from NSCAT winds. The identification and location of fronts using satellite remote sensing has long been a topic of great interest. Visible and IR imagery has taught us a great deal about the structure and evolution of extratropical cyclones [Carlsan, 1980; Browning and Roberts, 1994]. This type of imagery, however, has one inherent drawback. Broad cloud cover at higher levels obscures features at lower levels and at the surface. Only in well-organized, sharply defined systems can the approximate location of surface fronts be found from such passive sensors. Katsaros et al. [1996] used parameters from active/passive microwave sensors aboard Special Sensor Microwave Imager (SSM/I), Geosat, and ERS-1 satellites to study the evolution of marine cyclones. They found that frontal zones could be identified by large gradients in the SSM/I integrated water vapor. Unfortunately, this parameter is a measure of water vapor over the entire atmospheric column and cannot isolate features at the surface. The location of fronts changes with height because of the sloped surface of the interface between air masses. Consequently, the integrated water vapor can only identify a broad frontal zone representative of many levels rather than a sharp line at the surface. Katsaros et al. [1996] also used Geosat and ERS-1 altimeter wind speeds to identify wind speed gradients in the vicinity of fronts. These 

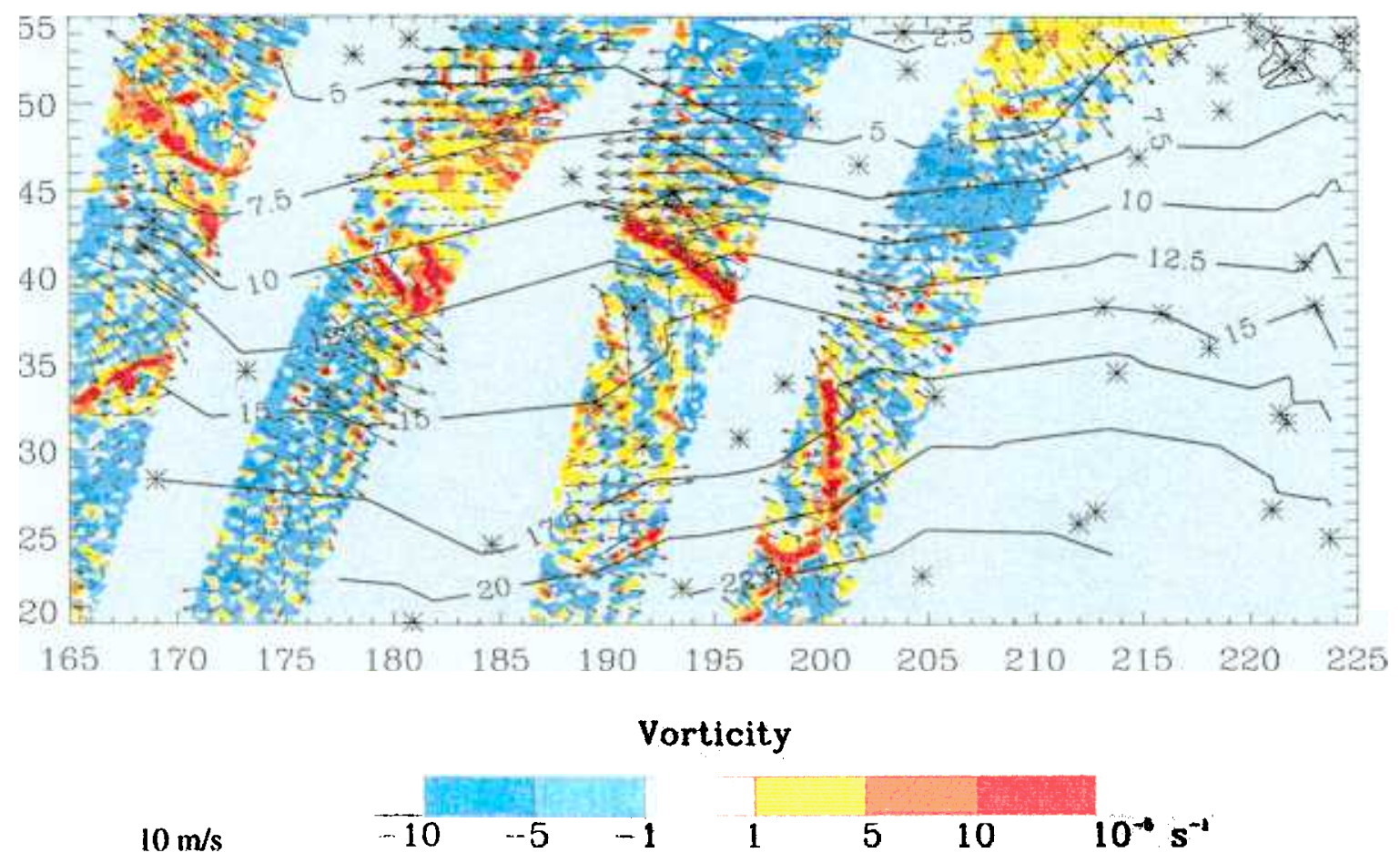

Plate 2. NSCAT winds and relative vorticity from two satellite passes around 1800 UTC, December 20 , 1996. Isotherms (degrees Celsius) are from NCDC ship and buoy data (asterisks mark individual observations). A cold front is identified by the band of high relative vorticity (red) in the right swaths.

altimeter data were often obscured by precipitation in the area of interest, especially in the frontal zones.

Surface fronts can be identified in NSCAT winds by changes in wind speed and direction. These changes are often subtle, though, making the exact location of a front difficult to determine by visual examination of the wind fields. When relative vorticity is computed from NSCAT winds, however, even subtle changes in wind speed and direction lead to large values of relative vorticity $\left(>1 \times 10^{-4} \mathrm{~s}^{-1}\right)$. Fronts are characterized by relatively low pressure at the boundary where air masses of higher pressure meet. Winds curve cyclonically in response to the localized pressure minimum, resulting in high positive relative vorticity values (in the Northern Hemisphere).

Plots of relative vorticity in the NSCAT swaths are presented showing linear bands of high relative vorticity near-surface fronts. The dual swaths of NSCAT winds and relative vorticity (Plate 2) show a mature cyclone at 1800 UTC December 20 , 1996. The cyclone is centered near $38^{\circ} \mathrm{N}$ and $186^{\circ} \mathrm{E}$, as evidenced by the circulation center and high relative vorticity values. Unfortunately, the cyclone center is in the gap between

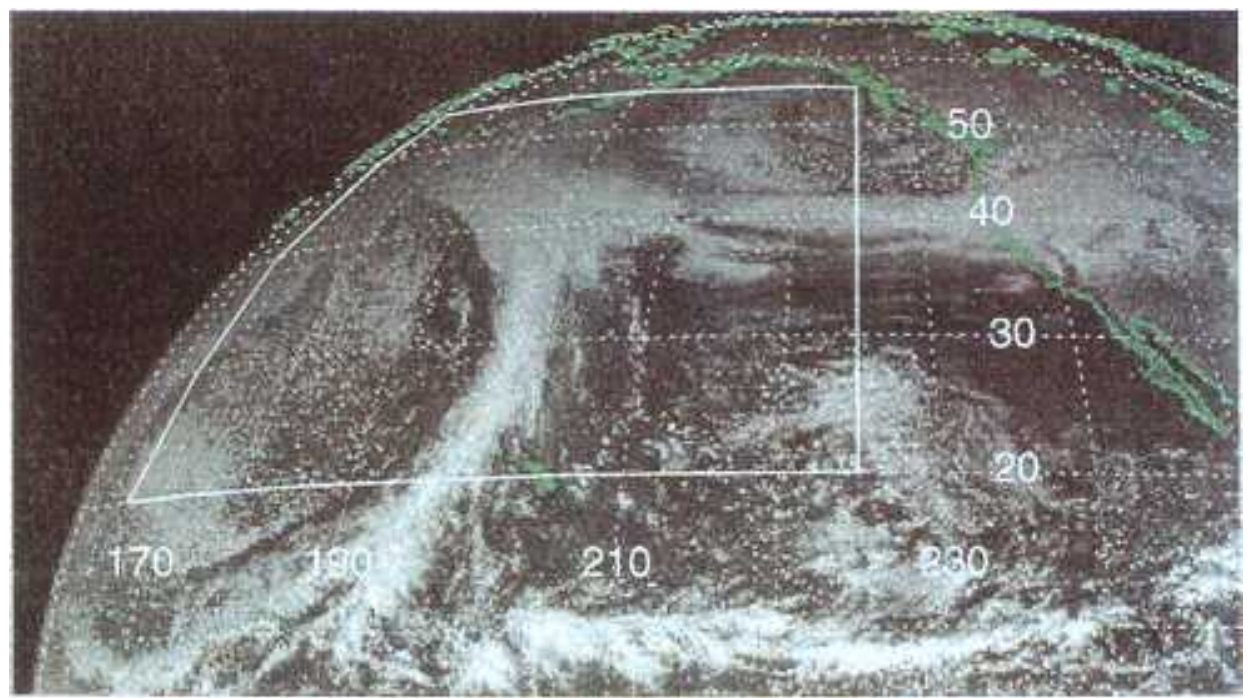

Plate 3. Goes 9 visible imagery from 1800 UTC, December 20, 1996. Solid white lines mark the study domain. 


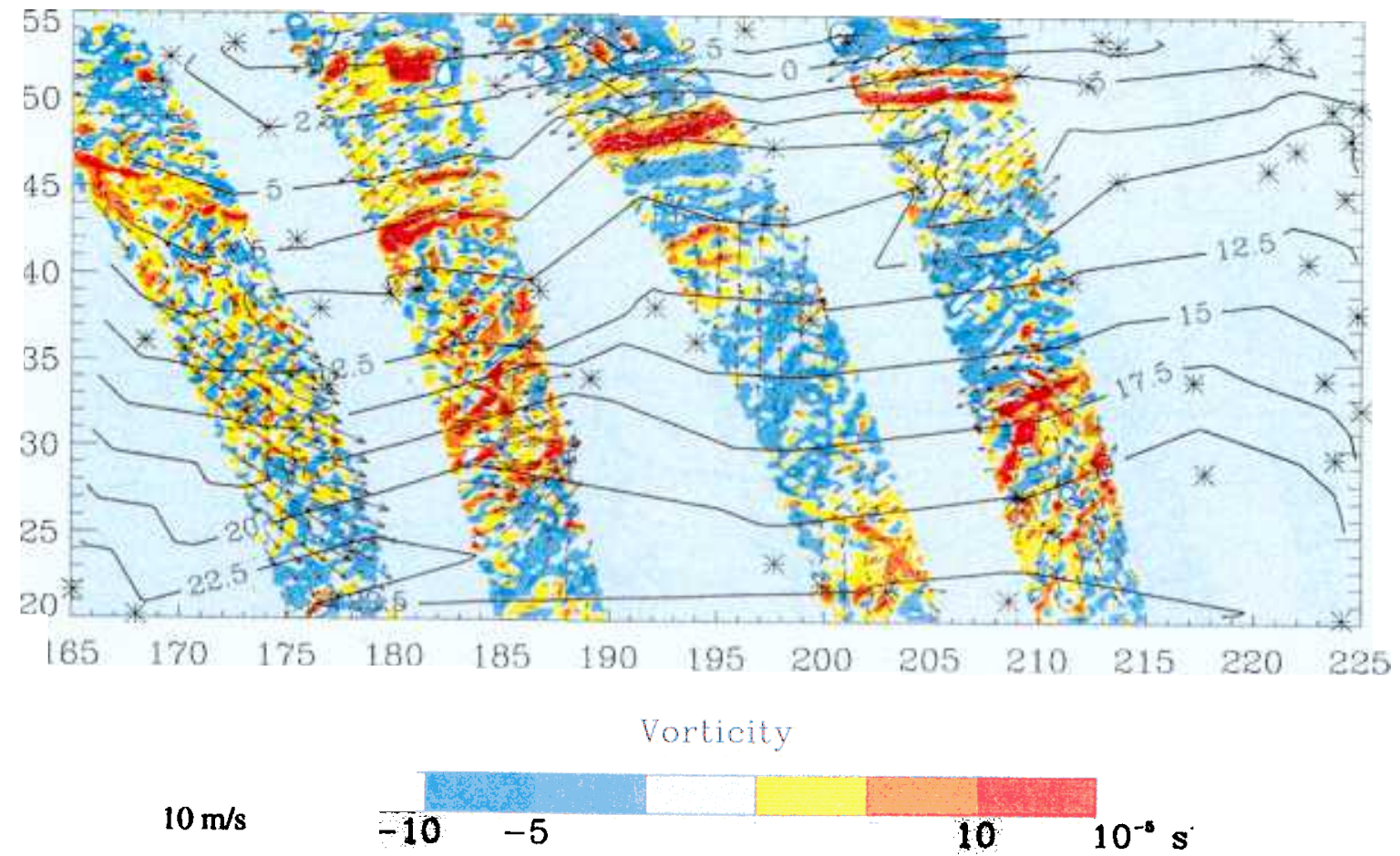

Plate 4. NSCAT winds and relative vorticity from two satellite passes around 1800 UTC, January 5, 1997. Isotherms (degrees Celsius) are from NCDC ship and bouy data (asterisks mark individual observations). A warm front extends form the cyclone center eastward across the northern portion of the domain.

the two passes of the satellite, and its exact location cannot be determined. A narrow band of high relative vorticity curves southeastward from near the cyclone center, possibly corresponding to the change in winds along a cold front. Rough contours of surface temperature made from National Climate Data Center (NCDC) ship and buoy observations verify a temperature drop behind this feature. Furthermore, GOES 9 visible imagery (Plate 3 ) shows a classic coma head at the low-pressure center and a band of cloudiness along the trailing cold front. These two independent data sources confirm that the high vorticity band is indeed a signature of the cold front.
Warm and stationary fronts have strong NSCAT relative vorticity signatures similar to those of cold fronts, though warm fronts are typically weaker. The NSCAT wind and relative vorticity fields from two passes of the satellite around 1800 UTC January 5, 1997, are plotted in Plate 4. A developing cyclone is roughty centered near $40^{\circ} \mathrm{N}$ and $185^{\circ} \mathrm{E}$, and a band of strong relative vorticity extends north and east from the center along a stationary front. There is a dramatic wind shift along this feature, with winds from the northeast on the north side and from the southwest on the south side. Surface temperature contours from NCDC surface observations show a

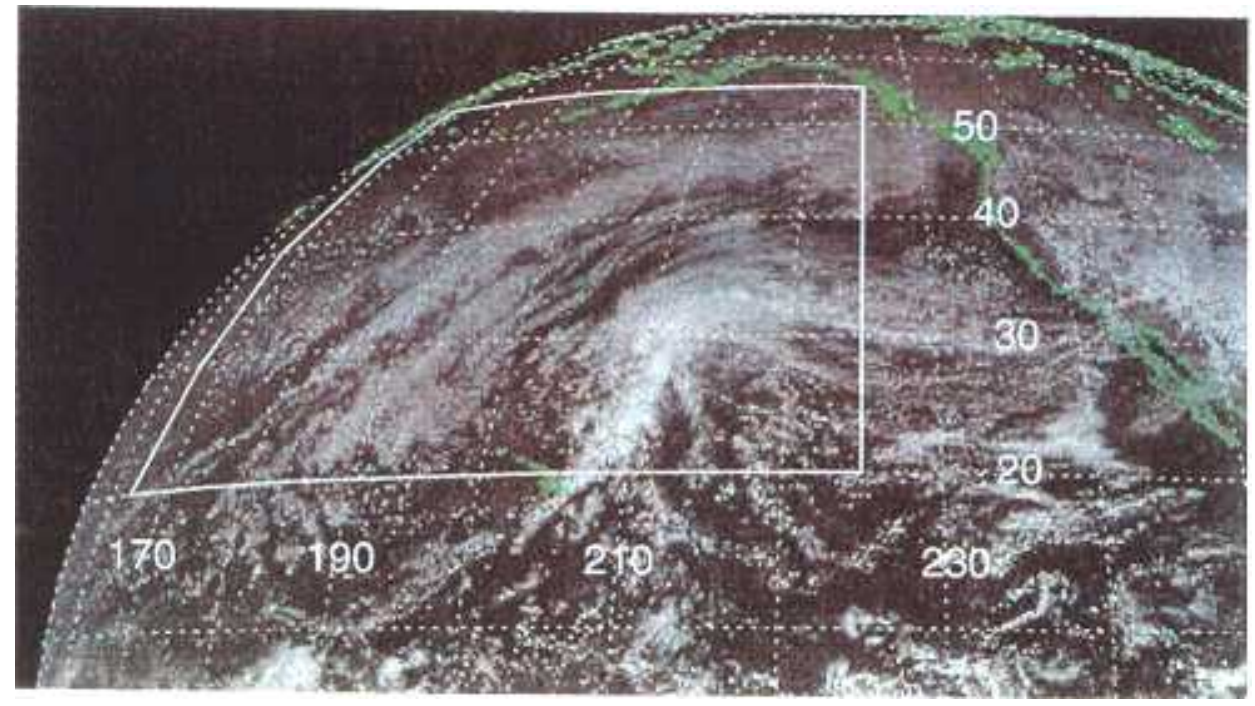

Plate 5. GOES 9 visible imagery from 1800 UTC, January 5, 1997. Solid white lines mark the study domain. 
strong temperature gradient from the high-vorticity line northward. GOES 9 visible imagery from the same time (Plate 5) shows a small cyclone near $30^{\circ} \mathrm{N}$ and $210^{\circ} \mathrm{W}$, which is also seen as a concentration of high relative vorticity at the same location in Plate 4. North and west of the small cyclone is a broad band of clouds that extends from $30^{\circ} \mathrm{N}$ and $185^{\circ} \mathrm{W}$ north and east across the entire domain. This cloud band corresponds well with the band of high relative vorticity in Plate 4 , confirming the presence of a stationary front that was first identified in the NSCAT relative vorticity. The NSCAT vorticity field succeeds in locating the front with $25-50 \mathrm{~km}$ using the resolution of the NSCAT winds and the width of the high vorticity band, which is more exact than other satellite data sources.

\subsection{Computing Geostrophic Vorticity}

The variational method requires NSCAT relative vorticity to be blended with the geostrophic vorticity of the initial pressure feld. Geostrophic vorticity is given by

$$
\zeta_{g}={ }_{\rho f} \nabla^{2} p+\frac{\beta}{f} u_{m}
$$

where $p$ is the surface pressure, $\rho$ is taken as a constant 1.225 $\mathrm{kg} \mathrm{m}^{-3}$ (U.S. standard atmosphere), $f$ is the Coriolis parameter, $\beta=d f / d y$, and $u_{g}$ is the zonal component of the geostrophic wind. In centered finite difference form, (2) becomes

$$
\begin{aligned}
& =\frac{1}{\rho f_{i}}\left(p_{i}+p_{i} \quad 2 p{ }^{\prime} \Delta x\right. \\
& \frac{1}{\rho f_{j}}\left(p_{i, j-1}+p_{4} \quad-2 p_{i j}\right) / \Delta y \\
& \frac{\beta}{f_{i}}\left(p_{L+}+p_{L_{j}} \quad 2 \Delta y\right.
\end{aligned}
$$

The initial guess for $\zeta_{\theta}$ is computed from the initial NCEP grid. For each subsequent step the pressure fields and all calcula. tions are performed on the $0.25^{\circ}$ grid.

\section{5}

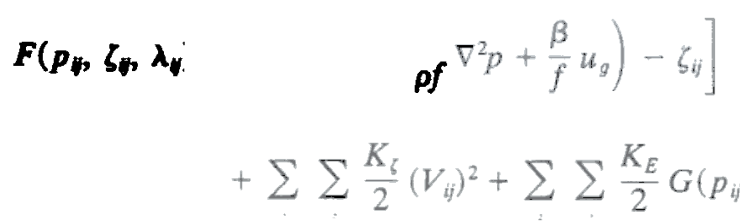

where the terms on the right-hand side are summed over all grid points $i$ and $j$. The first term on the right-hand side is commonly referred to as the model $\left(\zeta_{g}=(1 / \rho f) \nabla^{2} p+\right.$ $\left.(\beta / f) u_{g}\right)$, the unknown pressure and vorticity fields, multiplied by a Lagrange multiplier $\lambda_{i j}$. This term is known as a "strong constraint" [Saski, 1970]. The second term on the right-hand side minimizes the data misfits $V_{i j}$ between the new geostrophic vorticity $\zeta_{i j}$ and satellite vorticity (where available) and the misfits between the new and old geostrophic vorticities (outside the swaths).

In the swaths

$$
\bar{R} 6 \mathbf{s}
$$

Outside the swaths

$$
V_{i j}=\zeta_{i j}-\zeta_{i j}
$$

where $R$ is a reduction factor needed to increase the NSCAT relative vorticity to a geostrophic equivalent.

The NSCAT relative vorticity is a surface value that needs to be increased to a geostrophic equivalent before it is blended with geostrophic vorticity. A simple method for relating geostrophic or gradient winds to surface winds uses reductionrotation factors: Geostrophic winds are multiplied by a constant of 0.6-0.9, depending on boundary layer stability, and rotated counterclockwise $15^{\circ}-30^{\circ}$ [Clarke and Hess, 1975]. Harlan and O'Brien [1986] used a least squares method to find an average reduction constant of 0.83 and a rotation factor of $27.6^{\circ}$ between geostrophic and Seasat-A winds. Brown and Zeng [1994] used their boundary layer model to arrive at a reduction constant of 0.667 and a rotation factor of $18^{\circ}$ for neutral stratification. Herein $R$ is chosen to be 1.5 , equivalent to Brown and Zeng's reduction factor for neutral stability. The rotation factor is inconsequential since rotating NSCAT winds by a constant angle has no effect on relative vorticity values.

The last term on the right of (3) is a penalty function that acts to smooth horizontally the solution field. Without this term the only solution is $\lambda=0$, and satellite vorticity is inserted directly into the field. In general, the penalty function involves the second derivative of the solution field, often in the form of a Laplacian smoother. In this case, however, the Laplacian of $p$ is included in the model, and another penalty function must be used. The kinematic geostrophic kinetic energy $G\left(p_{i j}\right)$ is minimized [Harlan and O'Brien, 1986]:

$$
G\left(p_{q}\right)=\frac{1}{2}\left(u_{g}^{2}+v_{\rho}^{2}\right)=\frac{1}{2 \rho^{2} f^{2}} \nabla p \cdot \nabla p .
$$

The coefficients $K_{\zeta}$ and $K_{E}$ are weights that control the balance between the amount of smoothing to be done and the data misfits. The cost function must be minimized to arrive at the solution field $p_{i j}$ :

$$
\begin{aligned}
& \frac{\partial F}{\partial p_{i j}}=\frac{1}{p f}\left(\lambda_{i+1, j}+\lambda \quad 2 \lambda_{i j}\right) / \Delta x \\
& +\frac{1}{\rho f}\left(\lambda_{l, j+}+\lambda \quad-2 \lambda_{y}\right) / \Delta y \\
& +\frac{\beta}{\rho f}\left(\lambda_{i, j}+\lambda{ }_{-1}\right) / 2 \Delta y \\
& -\frac{K_{L}}{\rho^{2} f^{2}}\left[p \quad-p \lambda_{i}\right) / \Delta x \\
& \left.+\left(p+p \quad p \lambda_{1}\right) / \Delta y^{2}\right]=0 \\
& \frac{\partial F}{\partial \zeta_{U}}-\lambda_{\psi}+K_{\gamma} V_{\eta}=0 \\
& \frac{\partial F}{\partial \lambda_{i j}}=\left(\frac{1}{\rho f} \nabla^{2} p_{y}+\frac{\beta}{f} u_{i}\right)-\zeta_{i}=0
\end{aligned}
$$

Equation (8) can be written as

$$
\nabla^{2} \lambda_{i j}+\frac{\beta}{f}\left(\frac{\partial \lambda}{\partial y}=\frac{K_{E}}{2 \rho f} \nabla^{2} p_{V}\right.
$$


and has a solution of the form

$$
\lambda_{i j}=\frac{K_{E}}{2 \rho f}\left(p_{i j}-p_{0 i j}\right)
$$

where $p_{0 i j}$ is the homogeneous solution to (11) and thus satisfies $\left(K_{E} / 2 \rho f\right) \nabla^{2} p_{0 i j}=0$. On the boundaries, $\lambda=0$ and $p_{0 i j}=p i j$; therefore $p_{0 i j}$ can be found through successive overrelaxation given the boundary values from the initial pressure field. Combining (9) and (12) and letting $K=K_{E} / K_{\zeta}$ leads to

In the swath

$$
\zeta_{i j}=\zeta_{s_{q}}+\frac{K}{2 \rho f}\left(p_{i j}-p_{0 i j}\right)
$$

Outside the swath

$$
\zeta_{i j}=\zeta_{D v}+\frac{K}{2 \rho f}\left(p_{i j}-p_{0 i j}\right) .
$$

Substitution of (13) and (14) into (10) yields

In the swath

$$
\begin{gathered}
\frac{1}{\rho f_{j}}\left(p_{i+1, j}+p_{i-1, j}-2 p_{i j}\right) / \Delta x^{2}+\frac{1}{\rho f_{j}}\left(p_{i, j+1}+p_{i, j-1}-2 p_{i j}\right) / \Delta y^{2} \\
-\frac{\beta}{f_{j}^{2}}\left(p_{i, j+1}+p_{i, j-1}\right) / 2 \Delta y-\frac{K}{2 \rho f}\left(p_{i j}-p_{0 i j}\right)=\zeta_{S_{i j}}
\end{gathered}
$$

Outside the swath

$$
\begin{aligned}
& \frac{1}{\rho f_{j}}\left(p_{i+1, j}+p_{i-1, j}-2 p_{i j}\right) / \Delta x^{2}+\frac{1}{\rho f_{j}}\left(p_{i, j+1}+p_{i, j-1}-2 p_{i j}\right) / \Delta y^{2} \\
& -\frac{\beta}{f_{j}^{2}}\left(p_{i, j+1}+p_{i, j-1}\right) / 2 \Delta y-\frac{K}{2 \rho f}\left(p_{i j}-p_{0 i j}\right)=\zeta_{g i}
\end{aligned}
$$

which are solved using successive overrelaxation and constant normal derivative boundary conditions.

Lagrange multipliers $\lambda_{i j}$ often have a physical interpretation. For example, in (9) the Lagrange multipliers are equal to the data misfits. Results show that their spatial distribution is dominated by small-scale noise, with variations at 1 order of magnitude less than average vorticity values. No physical structures, such as the edges of the satellite swaths, are discernable in their spatial distribution. The Lagrange multipliers correspond to grid-scale vorticity differences brought about by the smoothing term in the variational method.

A stated earlier, $K$ is a coefficient that weights the relative contributions of the two constraints in the cost function. Furthermore, the two constraints are not dimensionally homogeneous, and the coefficient must account for the difference in units in the two terms. A value of $K=1 \times 10^{-13} \mathrm{~m}^{-2}$ produces a smooth pressure field while preserving the physical structures present in the NSCAT winds and relative vorticity. Higher values put too much weight on minimizing the geostrophic kinetic energy, resulting in a pressure field with gradients that are too relaxed.

\subsection{Boundary Conditions and Reference Pressures}

Solving (15) and (16) for surface pressure requires specification of boundary conditions on the borders of the domain. Harlan and O'Brien [1986] held the boundary pressure values constant (Dirichlet), setting them equal to the values from NCEP analyses. This condition was effective for their study because the feature of interest was located in the center of the study area. In the interior of the domain the solution field is loosely constrained by the boundary values, so their solution field realized the full influence of the assimilated scatterometer data over the low-pressure system. Also, they assimilated satellite data only once for each NCEP analysis, so their solution field was not required to evolve in time.

Neumann boundary conditions are used for this study. The pressure gradient normal to the boundary (as determined from NCEP reanalysis) is computed at each grid point along the border. Equations (15) and (16) are then solved holding these normal derivatives constant. This approach allows surface pressure values to change with the assimilation of NSCAT vorticity, even at and near the borders. The drawback of using derivative boundary conditions is that the spatial mean pressure is not constrained: The mean can drift from the initial value in a manner other than the true temporal evolution of the mean. The horizontal gradients and relative highs and lows in the solution field are realistic, but while assimilating one overpass, the spatial mean would drift between 0 and 6 mbar from ground truth. Without additional measures this error adds up quickly as the procedure is repeated for new satellite passes.

The drift in spatial mean pressure is remedied with reference pressures from within the domain. Ideally, the reference points would be located near the center of the study area and away from sharp horizontal pressure gradients or extreme features. A constant offset could then be added to or subtracted from the solution pressure field to make the solution and reference pressures equal at the reference points. Unfortunately, buoys are only located in the domain by Hawaii and the Aleutians, near the southern and northern borders of the domain (Figure 2). The offset is taken as the average of the differences between buoy and solution pressures at these points. Averaging reduces the influence of the locational errors in sharp gradients near the reference points.

The derivative boundary conditions still present limitations on the evolution of features near the borders: Large-scale features are not able to enter or leave the domain as the solution field evolves in time. For example, consider a lowpressure system entering the domain on the western border. To capture correctly this feature as it crosses the border, the normal derivative should change from positive (increasing toward the interior) to negative. For this reason the boundary conditions must be updated periodically. On the basis of domain size and the frequency with which new passes of the satellite occur, new derivative boundary conditions are computed from NCEP reanalyses every 12 hours. The 12 hour update cycle is chosen so that new boundary conditions are implemented at the synoptic times of 0000 UTC and 1200 UTC. Using additional NCEP data to update the boundary conditions does not lessen the dependency of the solution field on NSCAT vorticity data. It simply provides a framework of large-scale horizontal pressure gradients to govern the solution near the borders.

\subsection{Viability of the Technique}

A major goal of this study is to describe the evolution of cyclones based primarily on NSCAT observations. With the assimilation of data from each new pass of the satellite, less information is retained in the pressure field from the initial NCEP analysis. In 24 hours, seven to nine passes of the satellite over the domain cover $\sim 75 \%$ of the area (Figure 2 ). In 48 
hours the total is over $90 \%$, with a majority of the domain covered at least twice. At this point the geostrophic vorticity field is described almost exclusively by NSCAT vorticity. The solution pressure field follows from the geostrophic vorticity field, constrained only by the pressure field from the previous iteration, the derivative boundary conditions, and the two reference pressures. Continued assimilation of new satellite passes changes the geostrophic vorticity field (and corresponding pressure field) as physical features move about and evolve in the domain. Ideally, the process continues throughout the life cycle of the feature of interest.

The technique does, however, have two limitations. First, the feature (cyclone, front, etc.) must have a strong signature in the satellite vorticity field. Results show that high values of relative vorticity are concentrated at frontal zones and cyclone centers. If the feature is weak or diffuse, noise and small-scale variations in the NSCAT relative vorticity overwhelm the large-scale structure of the feature. The solution field diverges from the true surface pressure field, and this problem is compounded as more satellite passes with weak vorticity patterns are assimilated. Also, cells contaminated by attenuation from liquid water introduce error into the vorticity field. These errors do not appear to affect greatly the solution pressure fields for strong systems as the attenuation errors are more local in nature and may not influence the large-scale structure of the pressure field. It is impossible, however, to determine the exact impact of the attenuation problem on the vorticity and pressure fields without knowing which cells are contaminated.

The technique also breaks down when the feature moves too quickly through the study area. Consider a cyclone moving west to east through the domain at $10 \mathrm{~m} \mathrm{~s}^{-1}$. On the first day the satellite records an area of high relative vorticity corresponding to the center at a longitude of $175^{\circ} \mathrm{E}$. This feature is assimilated into the pressure field and results in a low-pressure center at that location. The satellite may not pass over the feature again in 24 hours. Meanwhile, the true center of the cyclone would have moved nearly $800 \mathrm{~km}$. If the satellite now passes over the center at its new position while missing its old position, the resulting pressure field will erroneously show the feature as an elongated or two-centered system. The coverage from NSCAT is insufficient to capture the movement of the cyclone properly, and the solution field diverges from the true pressure field. It is foreseen that QuikSCAT, with its wider coverage and no nadir gap, will alleviate much of this problem, particularly when multiple scatterometers are in operation.

\section{Case Studies}

\subsection{Case 1: December 18-24, 1996}

The method is first applied to a case of cyclogenesis that occurred December 18-24, 1996. The NCEP surface pressure analysis from 0000 UTC, December 18, 1996, initializes the process. The solution pressure field (hereafter call NSCAT pressure) evolves with the assimilation of data from 52 satellite passes over 7 days. Snapshots of the NSCAT pressure field are compared to NCEP reanalyses nearest in time to the latest satellite pass. Also, both the NSCAT and NCEP pressure fields are checked for consistency with the NSCAT wind vectors from the latest satellite pass. This comparison does not constitute validation of the NSCAT pressure fields, as an independent data source is necessary for objective results. It is simply intended to show how the NSCAT pressure fields conform to features seen in the NSCAT wind fields.
The first satellite pass covers only a small corner of the domain. The NSCAT pressure field changes very little from the NCEP initialization, aside from smoothing the discontinuities caused by NCEP's coarse $2.5^{\circ}$ grid (Figure 3a, 0000 UTC December 18, 1996). This iteration demonstrates how the field retains the characteristics of the previous step over areas where no new satellite information is available for assimilation. After the assimilation of eight passes the NSCAT pressure field evolves considerably (1800 UTC, December 18, 1996). The low-pressure system near the northern border weakens, while the low-pressure system near the southern border deepens in response to the strong vorticity values from the last satellite pass. The NCEP analysis from the same time does not intensify this system, yet shows a higher central pressure (1003 mbar compared to 997 mbar) than the NSCAT field. Also, notice how the isobars tend to "kink" where winds turn sharply in response to features of high vorticity. Sharp bends in pressure contours are indicative of a sudden change in horizontal gradient, often associated with frontal zones [Djuric, 1994].

At 1200 UTC, December 20, 1996, the cyclone reaches its mature stage (Figure 3c). The NSCAT central pressure is 989 mbar, close to NCEP's value of 987 mbar. NCEP locates the center at $38^{\circ} \mathrm{N}$ and $186^{\circ} \mathrm{E}, 1^{\circ}$ east of the circulation center as determined from the NSCAT wind vectors. The NSCAT pressure field places the center at $37^{\circ} \mathrm{N}$ and $185^{\circ} \mathrm{E}, 1^{\circ}$ east and south of the circulation center. The only other difference in the two pressure fields is that NSCAT builds higher pressure at the northern edge of the domain, over 1050 mbar. The NCEP analysis only has pressures in this area of a little over 1040 mbar. Elsewhere, the tow fields agree well in the overall structure and the placement of major surface features. The NSCAT field has been able to capture correctly the intensifying system with only the assimilation of NSCAT relative vorticity and updated boundary conditions.

By 1200 UTC, December 21, 1996 (Figure 4a), NCEP weakens the system to a central pressure of 994 mbar. The cyclone is now stretched along a major axis running northwest to southeast. The center is not well defined and is displaced from the circulation center by $5^{\circ}$ to the north and $3^{\circ}$ to the west. NSCAT keeps a central pressure of 987 mbar and correctly locates the center at $38^{\circ} \mathrm{N}$ and $188^{\circ} \mathrm{E}$, coincident with the center of circulation of the NSCAT wind vectors. Both fields have tight pressure gradients on the northeast side of the cyclone, which agrees well with the strong southeasterly winds in this area. The orientations of the NSCAT pressure contours are more consistent with the wind vectors from the last satellite pass, especially just north of the circulation center.

Figure 4b depicts the pressure fields at 1800 UTC, December 22,1996 , after the assimilation of 40 satellite passes over 5 days. The two pressure fields now agree on the cyclone's central pressure of 993 mbar. NCEP correctly locates the cyclone center at the center of circulation, while NSCAT has a double low. The tightest gradients and strongest winds are now on the western side of the cyclone. Both fields also exhibit kinking of the isobars along the cold front, which extends to the south and east of the cyclone center.

Two days later, at 1200 UTC, December 24, 1996, the cyclone reintensifies with a central pressure of 992 mbar. The storm is large, nearly covering the entire domain. NSCAT and NCEP are in good agreement with both the location and intensity of the cyclone center, with NCEP being a little deeper at 989 mbar. Both fields are consistent with the NSCAT wind vectors. A warm frontal zone now extends eastward from the 
(a)

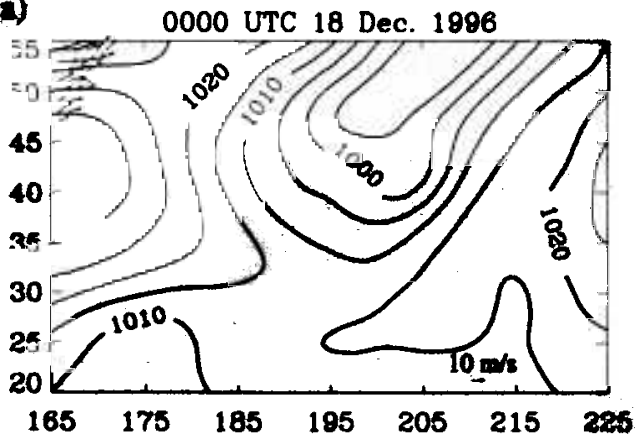

(b)

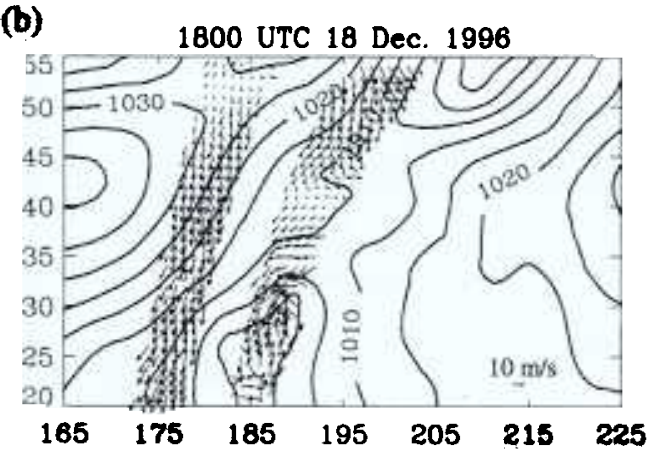

(c)

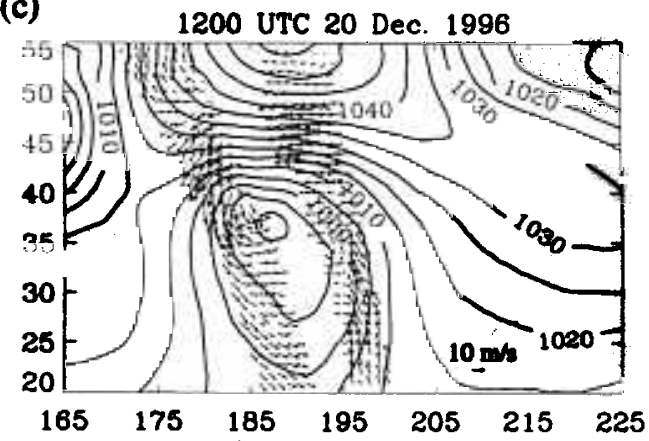

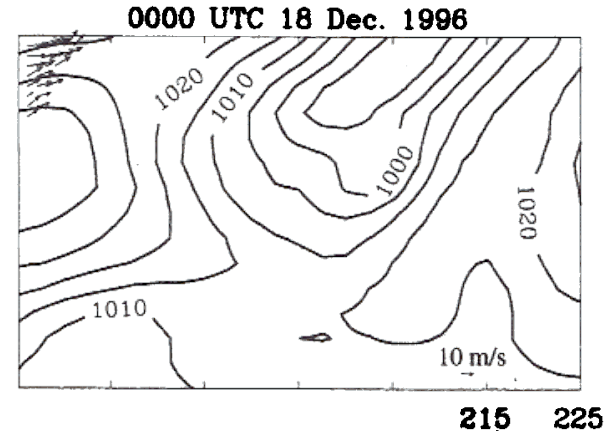
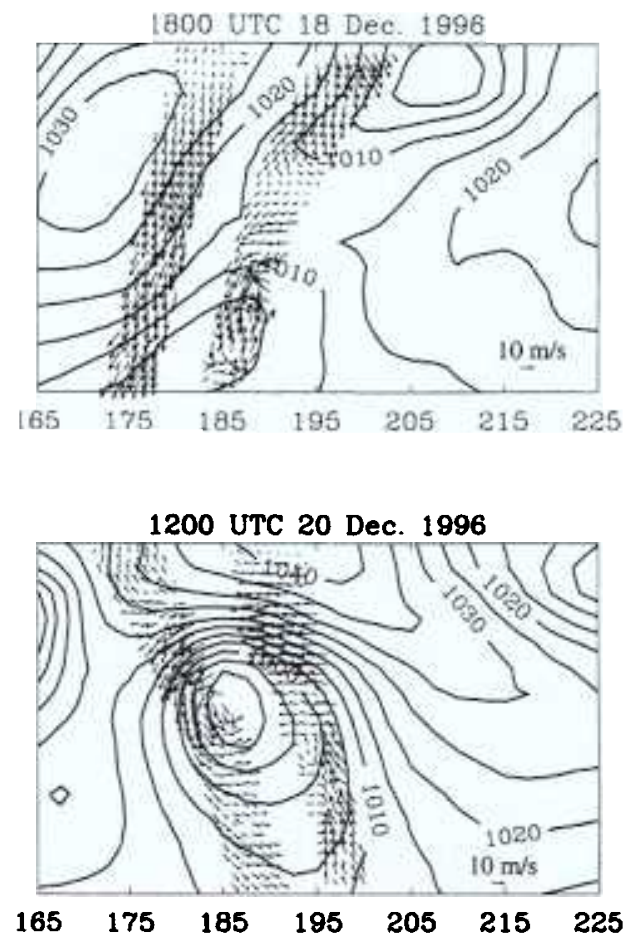

Figure 3. Case 1: NSCAT surface pressure field (mbar) after the assimilation of (a) 1, (b) 8 , and (c) 20 satellite passes: (left) NSCAT wind vectors from the last satellite pass and (right) concurrent NCEP reanalysis surface pressures.

cyclone's center. The NSCAT pressure field resolves this feature sharply as seen in the 995 and $\mathbf{1 0 0 0}$ mbar contours and strong pressure gradients normal to the front. The NCEP analysis has gently curving contours in this zone, making the exact location of the front difficult to determine.

\subsection{Case 2: January 3-6, 1997}

This is a case of frontogenesis that took place during January 3-6, 1997. The process is initialized at 0000 UTC, January 3, 1997 , when the only feature of interest is a weak low-pressure system centered at $48^{\circ} \mathrm{N}$ and $177^{\circ} \mathrm{E}$ (Figure 5a). The NSCAT pressure field picks up another low-pressure lobe entering the domain on the western border at $40^{\circ} \mathrm{N}$. This feature is not seen in the NCEP reanalysis.

Figure 5b shows 1800 UTC, January 3, 1997. The low moves east and, according to the NSCAT pressure field, is centered at $50^{\circ} \mathrm{N}$ and $190^{\circ} \mathrm{E}$ with a central pressure of 994 mbar. The NCEP analysis places the center $2^{\circ}$ south and east of the NSCAT location with a central pressure of 987 mbar. The
NSCAT low-pressure center location exactly matches the center of circulation. NSCAT also does a better job of showing the elongated nature of the low, especially on the eastern end. Notice how the wind vectors parallel the NSCAT pressure contours in this area. NCEP does not extend the low far enough east, as the wind vectors cross the contours at unrealistically large angles, flowing from low to high pressure.

The low moves little in the next 18 hours (Figure 5c). The center is now located at $49^{\circ} \mathrm{N}$ and $192^{\circ} \mathrm{E}$ in the NSCAT pressure field, coincident with the center of circulation. NCEP continues to place the center too far to the east by $2^{\circ}$. Both fields have a central pressure of 983 mbar. The NCEP analysis places another distinct low at $42^{\circ} \mathrm{N}$ and $172^{\circ} \mathrm{E}$, where the NSCAT field has a more continuous trough extending east to west across the northern portion of the domain. Six hours later, at 1800 UTC, January 4, 1997, an apparent front has formed and extends across the northern portion of the study area (Figure 6a). The front in the NSCAT pressure field is defined 

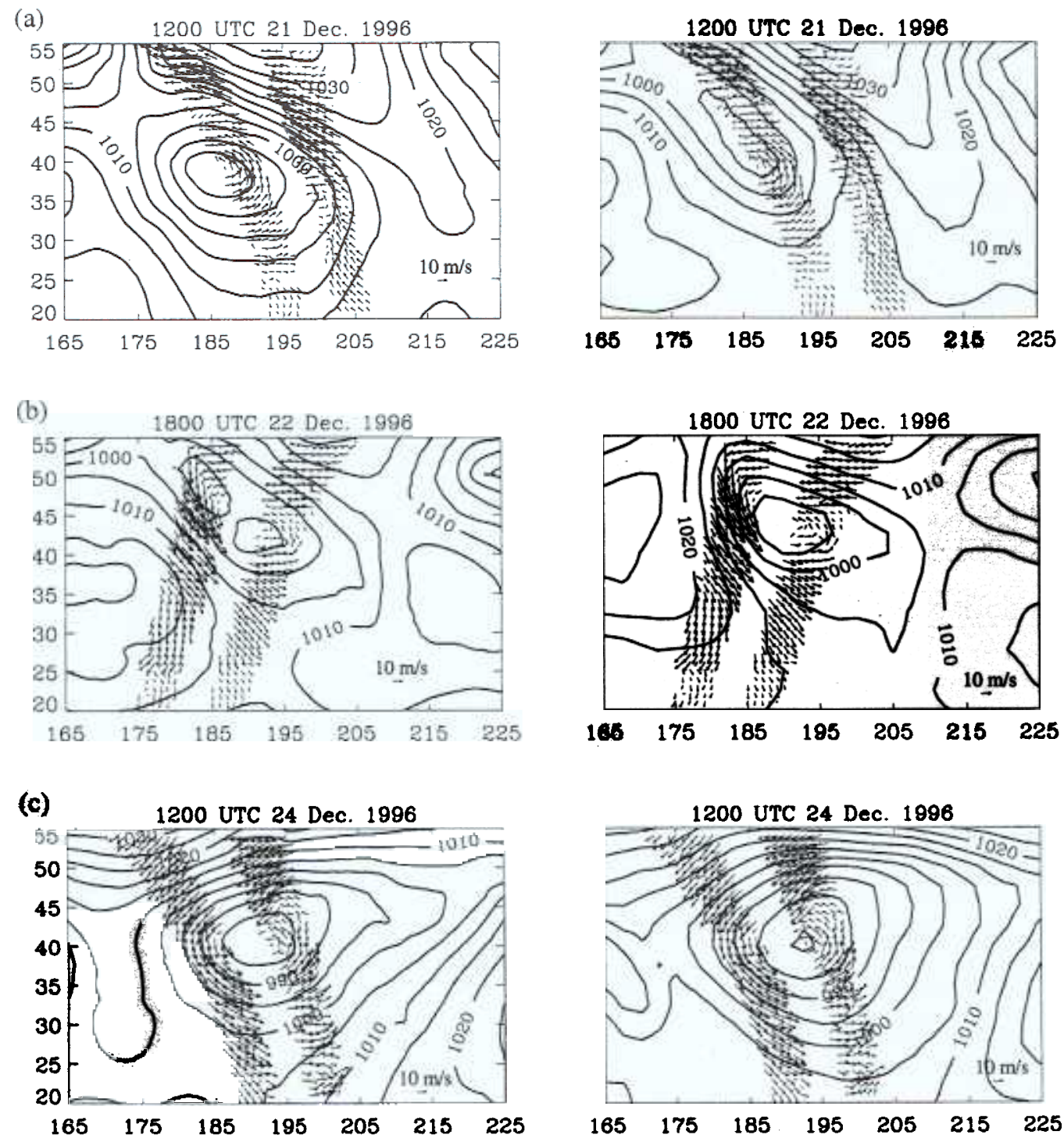

Figure 4. Same as Figure 3 but for the assimilation of (a) 29, (b) 40, and (c) 52 satellite passes.

by a nearly continuous band of high vorticity and low pressure. North of the front, the winds are east-northeast, while south of the front, they are from the west-southwest. Also, pressure gradients have tightened on both sides of the front. The wind shift line coincides well with the line of lowest pressures. The NCEP analysis persists in separating the feature into two different lows. NSCAT wind vectors show no evidence of closed circulation around either of the features to support this analysis.

The front is nearly stationary for the next 24 hours and is sharply delineated by the 1800 UTC, January 5, 1997, NSCAT pressure field. The wind shift across the front from northeast to southwest is highly localized along the length of the front. NCEP finally merges the two lows into one elongated feature, although it is not as linear as was depicted by the NSCAT pressure field. The NCEP analysis has slightly lower pressure (986 mbar) than NSCAT (989 mbar) on the western portion of the front. Otherwise, the NSCAT positions of two small lowpressure features along the front agree well with the wind circulation patterns.

At 1800 UTC, January 5, 1997, the westernmost lobe of low pressure is developing into a new cyclone (Figure $6 \mathrm{c}$ ). Winds now curve gently around the western side of the center rather than shifting sharply as in earlier swaths. Also, beginning at 1200 UTC, January 5, 1997, a new windshift line forms to the southeast of the center, corresponding to the genesis of a trailing cold front (Figure 6b). This feature is seen in the NSCAT pressure field as a sharp trough extending south of the cyclone center. NCEP does not resolve the front, showing only gently curved isobars with the trough axis placed $10^{\circ}$ east of the NSCAT position.

\subsection{Accuracy of the NSCAT and NCEP Pressure Fields}

Two generalizations can be made about the NSCAT pressure field from these case studies. First, the field is more realistic in the interior of the domain than near the boundaries. New features moving into the domain are not assimilated into the NSCAT pressure field until the satellite passes over the area, so these features may be totally missed. Also, regions near the borders are constrained by the boundary conditions. Away from the borders, the solution fieid is free to conform to features found in the NSCAT relative vorticity. Second, the NSCAT pressure field is more accurate where the satellite has 
(a)

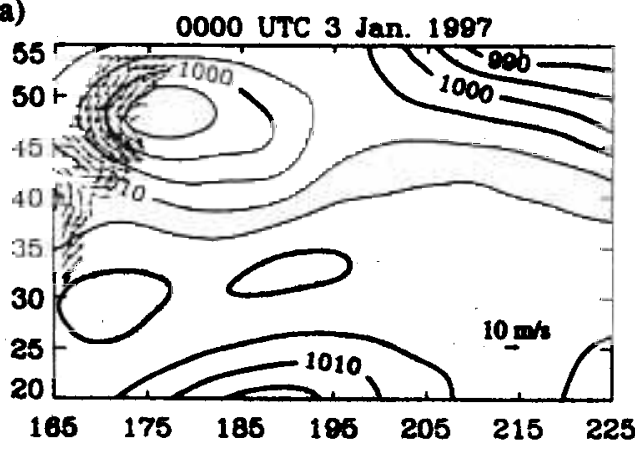

(b)

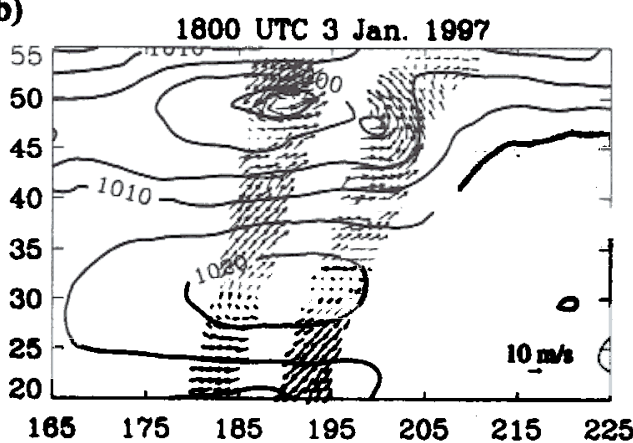

(c)

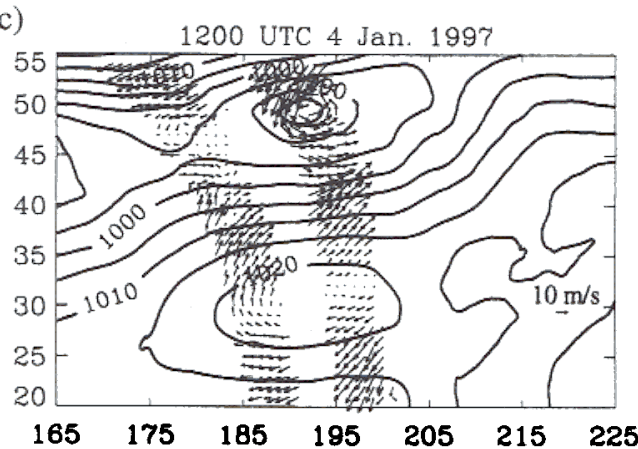

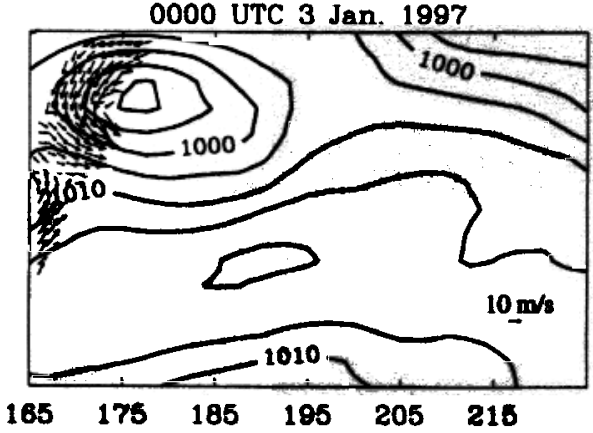

1800 UTC 3 Jan. 1997
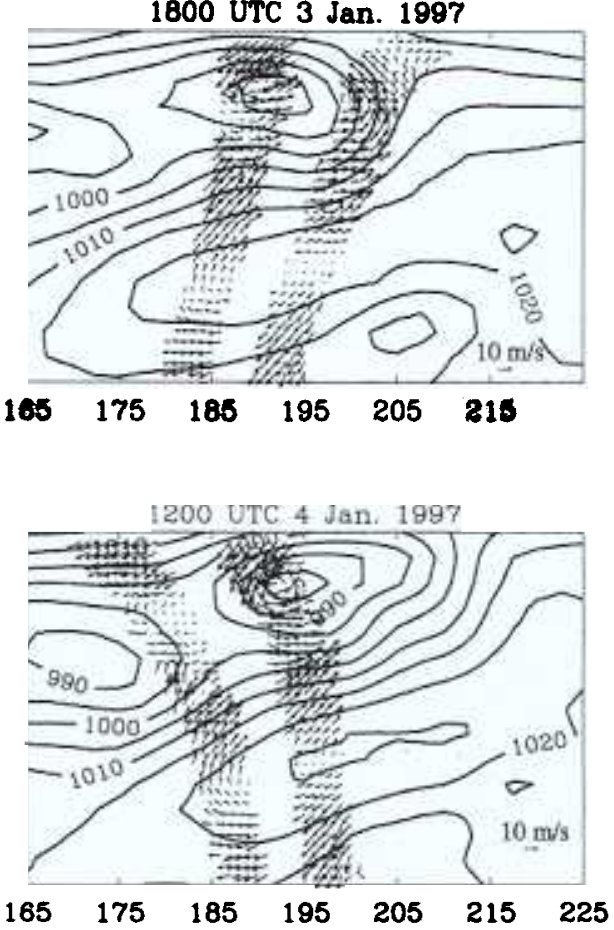

Figure 5. Case 2: NSCAT surface pressure field (mbar) after the assimilation of (a) 1 , (b) 7 , and (c) 12 satellite passes: (left) NSCAT wind vectors from the last satellite pass and (right) concurrent NCEP reanalysis surface pressures.

passed more recently. It stands to reason that the portion of the domain updated with newer information is more current than an area that has not seen a satellite pass in many hours.

Table 1 addresses the accuracy of both the NSCAT and NCEP pressure fields. Three hourly surface pressure observations from ships and buoys (courtesy of the NCDC are compared to values from both the NSCAT and NCEP pressure fields for each snapshot in Figures 3-6. For each case the mean and standard deviation of the difference between the pressure field values and the in situ observations are computed using all available observations for that time. These statistics are computed for all observations in the interior of the domain (at least $5^{\circ}$ from the boundaries). The results show that the NCEP pressure field is quantitatively more accurate than the NSCAT field. The NSCAT mean difference ranges from 0.1 to $2.5 \mathrm{mbar}$ in magnitude, and the standard deviation is between 2.4 and 6.1 mbar. The NCEP mean difference is small, between 0.1 and $1.2 \mathrm{mbar}$, and the standard deviation is $\leq 5.8 \mathrm{mbar}$. NCEP should be more accurate for several reasons. First, the ship and buoy observations are used by NCEP in their reanalyses, so the two are not independent. Second, the observations were made at the same synoptic times as the NCEP analyses. The NSCAT pressure field, however, may have seen the last satellite pass as far as \pm 3 hours of the synoptic time. Also, the NSCAT pressure field outside the area covered by the latest pass is based on older satellite information, 12-24 hours from the latest pass. Yet another source of error in the NSCAT field is the scarcity of reference pressures. Only two buoys were available, and these are both located in the eastern half of the domain. Inaccuracies in the pressure gradients caused by older satellite data lead to increasing errors with distance from the reference points. The result that NSCAT pressure fields have mean differences and standard deviations only slightly higher than NCEP's reanalysis product supports the validity of the variational method in deriving surface pressures from NSCAT winds.

Although the NSCAT pressures may not be quantitatively more accurate than NCEP over the domain as a whole, the 

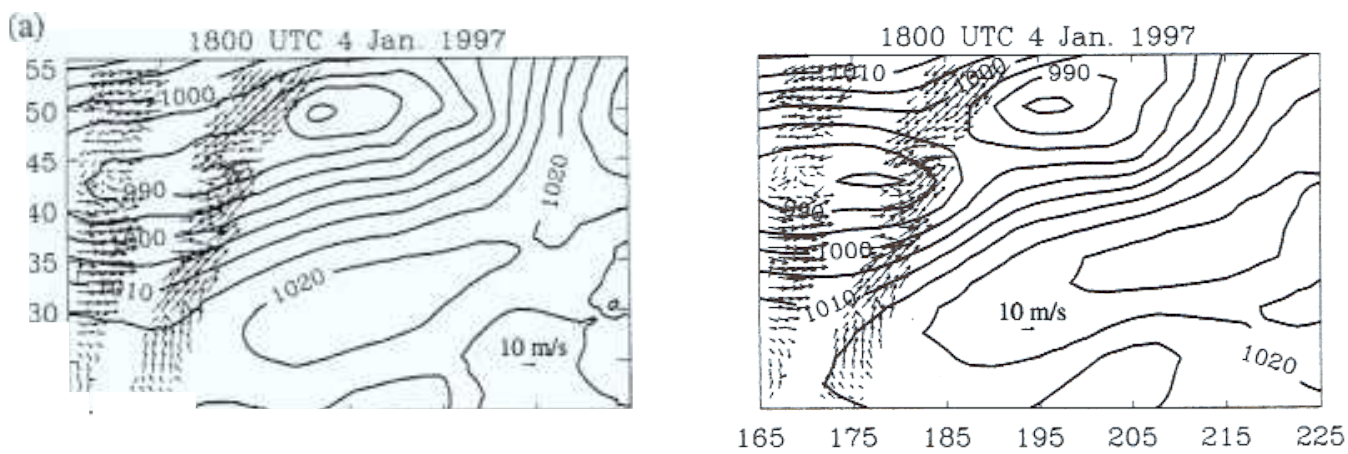

(b)
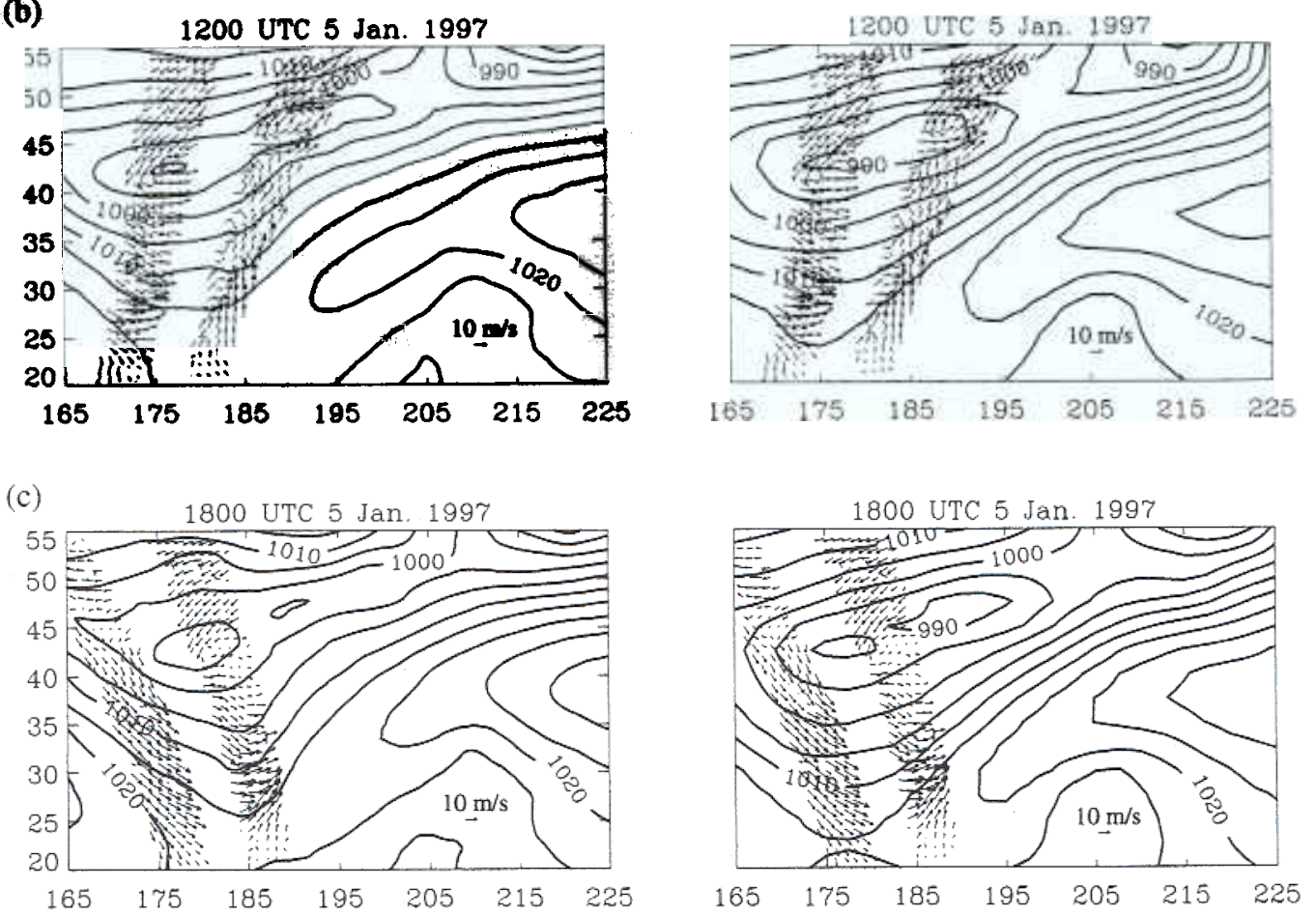

Figure 6. Same as Figure 5 but for the assimilation of (a) 18, (b) 22, and (c) 27 satellite passes.

qualitative advantages are seen in the detailed comparisons made in sections 4.1 and 4.2. Features such as fronts are more sharply defined, and pressure gradients are more consistent with the NSCAT winds. The improved detail in the geostrophic vorticity fields gives rise to features in the NSCAT pressure fields that are blurred or not seen at all in the NCEP analyses.

NSCAT is also better at placing the low-pressure centers correctly with respect to the center of circulation of the

Table 1. Comparison With Surface Data

\begin{tabular}{|c|c|c|c|c|c|}
\hline \multirow[b]{2}{*}{ Time and Date } & \multicolumn{2}{|c|}{ NSCAT Interior } & \multicolumn{2}{|c|}{ NCEP Interior } & \multirow[b]{2}{*}{$\begin{array}{c}\text { Number of } \\
\text { Observations }\end{array}$} \\
\hline & $\begin{array}{c}\text { Mean } \\
\text { Difference, } \\
\text { mbar }\end{array}$ & $\begin{array}{c}\text { Standard } \\
\text { Deviation, } \\
\text { mbar }\end{array}$ & $\begin{array}{c}\text { Mean } \\
\text { Difference, } \\
\text { mbar }\end{array}$ & $\begin{array}{c}\text { Standard } \\
\text { Deviation, } \\
\text { mbar }\end{array}$ & \\
\hline $\begin{array}{l}1800 \text { UTC, Dec. } 18 \\
1200 \text { UTC, Dec. } 20 \\
1200 \text { UTC, Dec. } 21 \\
1800 \text { UTC, Dec. } 22 \\
1200 \text { UTC, Dec. } 24 \\
1800 \text { UTC, Jan. } 3 \\
1200 \text { UTC, Jan. } 4 \\
1800 \text { UTC, Jan. } 4 \\
1200 \text { UTC, Jan. } 5 \\
1800 \text { UTC, Jan. } 5\end{array}$ & $\begin{array}{r}-0.2 \\
1.5 \\
-0.7 \\
-0.1 \\
2.0 \\
1.0 \\
-0.2 \\
-2.5 \\
-0.8 \\
2.0\end{array}$ & $\begin{array}{l}2.4 \\
6.1 \\
6.1 \\
6.0 \\
3.3 \\
6.1 \\
5.5 \\
5.4 \\
4.6 \\
4.1\end{array}$ & \begin{tabular}{r|}
-0.2 \\
0.2 \\
0.6 \\
-0.1 \\
0.2 \\
1.2 \\
0.2 \\
0.0 \\
-0.3 \\
-0.2
\end{tabular} & $\begin{array}{l}1.7 \\
42 \\
3.2 \\
1.4 \\
2.2 \\
5.8 \\
4.7 \\
4.3 \\
2.5 \\
3.0\end{array}$ & $\begin{array}{l}39 \\
34 \\
29 \\
37 \\
37 \\
35 \\
34 \\
32 \\
33 \\
48\end{array}$ \\
\hline
\end{tabular}


Table 2. Difference in the Locations of Low-Pressure Centers Compared to Centers of Circulation

\begin{tabular}{|c|c|c|c|c|c|c|}
\hline \multirow[b]{2}{*}{ Time and Date } & \multicolumn{3}{|c|}{ NSCAT } & \multicolumn{3}{|c|}{ NCEP } \\
\hline & $\begin{array}{l}\text { Latitude, } \\
\text { deg. }\end{array}$ & $\begin{array}{c}\text { Longitude, } \\
\text { deg. }\end{array}$ & $\begin{array}{c}\text { Distance, } \\
\mathrm{km}\end{array}$ & $\begin{array}{c}\text { Latitude, } \\
\text { deg. }\end{array}$ & $\begin{array}{c}\text { Longitude, } \\
\text { deg. }\end{array}$ & $\begin{array}{c}\text { Distance, } \\
\mathrm{km}\end{array}$ \\
\hline 1200 UTC, Dec. 20 & & 2.0 & 280 & & 2.0 & 170 \\
\hline 1800 UTC, Dec. 20 & & 0.0 & 0 & & 1.0 & 140 \\
\hline 1200 UTC, Dec. 21 & & 1.0 & 85 & & 3.0 & 420 \\
\hline 1200 UTC, Dec. 22 & & 1.0 & 140 & & 3.0 & 600 \\
\hline 1800 UTC, Dec. 22 & & 0.0 & 225 & & 0.0 & 0 \\
\hline 1200 UTC, Dec. 23 & & 2.0 & $\overline{170}$ & & 2.0 & 170 \\
\hline 1800 UTC, Dec. 23 & & 0.0 & 0 & & 0.0 & \\
\hline 1200 UTC, Dec. 24 & & 0.0 & 0 & & 0.0 & 0 \\
\hline 1800 UTC, Jan. 3 & & -1.0 & 85 & & 20 & 200 \\
\hline 1200 UTC, Jan. 4 & & 0.0 & 0 & & 2.0 & 170 \\
\hline Average & & 0.7 & 100 & & 1.5 & 190 \\
\hline
\end{tabular}

NSCAT winds. An independent data source would lead to a more objective comparison, but the lack of conventional data over the North Pacific makes the NSCAT wind vectors the best alternative for determining the correct location of low-pressure centers. Table 2 shows the difference in location of lowpressure centers compared to circulation centers for times when the circulation center is revealed in the latest satellite path. In 2 of the 10 cases both NSCAT and NCEP agree exactly with the NSCAT winds. In the first case, at 1200 UTC, December 1996, the NSCAT low-pressure center is placed 280 $\mathrm{km}$ from the circulation center. This displacement is caused by an older vorticity maximum lying between the two swaths of a new pass, giving a false vorticity signature to the new NSCAT pressure field (section 4.1). Other than this isolated case, NSCAT low-pressure centers are consistently closer to the circulation centers than NCEP. On average, NSCAT lowpressure centers are $100 \mathrm{~km}$ from the circulation center, while NCEP averages $190 \mathrm{~km}$ errors. And interesting feature of Table 2 is the trend in longitudinal error of the NCEP analyses. In 7 out of the 10 cases the NCEP center is placed too far eastward when compared to circulation centers and in no case is it displaced to the west. While 10 cases (two different systems) are too few to suggest a systematic bias in the NCEP analyses, the trend warrants further investigation.

\section{Conclusions}

A variational method is devised to generate surface pressure fields from NSCAT winds. The method solves for a surface pressure field by smoothly blending relative vorticity computed from NSCAT winds with ambient geostrophic vorticity. The method ignores the ageostrophy of surface winds as no upper air thermal or mass fields are used to make adjustments. The solution pressure field is updated as new passes of the satellite over the study area provide additional information. Neumann boundary conditions, updated twice daily with NCEP normal gradients, allow the surface pressure field to evolve in time.

This method is used to study a case of cyclogenesis and a case of frontogenesis in the North Pacific. The NSCAT pressure fields correctly capture these features as they intensify and move through the study area. The NSCAT pressure fields are qualitatively compared to NCEP reanalysis surface pressure fields, and both fields are quantitatively compared to NCDC ship and buoy observations. The domain-averaged differences between NSCAT pressures and surface observations range from 0.1 to 2.5 mbar in magnitude with a standard deviation between 2.4 and 6.1 mbar. NCEP pressures compare slightly better, with mean differences below 1.2 mbar in magnitude and standard deviations below 5.8 mbar. The accuracy of the NSCAT pressure fields increases near the latest satellite swaths and in the interior of the domain.

Qualitatively, the NSCAT pressure fields resolve the structure of cyclones and fronts more realistically and with greater detail than the NCEP analyses. The NCEP model and other spectral models generally represent fronts as broad transition zones because of their coarse resolution. The NSCAT winds and resultant surface pressure fields better represent fronts as boundaries because of their high spatial resolution. Also, the centers of cyclones are placed more accurately in the NSCAT pressure fields than in NCEP analyses when compared to the centers of circulation from NSCAT winds. The average difference is $100 \mathrm{~km}$ for NSCAT pressure fields and $190 \mathrm{~km}$ for NCEP analyses.

Another result of this study is the signature of surface fronts in relative vorticity fields computed from NSCAT winds. Fronts are clearly identified by linear bands of high relative vorticity values. These bands are verified as fronts using surface temperature gradients and satellite imagery. NSCAT vorticity fields locate the fronts with an accuracy of $25-50 \mathrm{~km}$ and with greater resolution than other satellite data sources.

Although NSCAT winds are a high-quality data source, effective techniques for assimilation into NWP models have proven difficult to develop. Surface pressure fields from NSCAT winds, however, could provide a more favorable assimilation source [Hoffman, 1993; Atlas, 1997]. This study brings forth a simple method for determining surface pressures from NSCAT winds and demonstrates its effectiveness.

Acknowledgments. Funding for this project is from the NASA JPL NSCAT project. COAPS receives its base funding from ONR's Secretary of the Navy Grant to James J. O'Brien.

\section{References}

Andrews, P. L., and R. S. Bell, Optimizing the United Kingdom Meteorological Office data assimilation of ERS-1 scatterometer winds, Mon. Weather Rev., 126, 736-746, 1998.

Anthes, R. A., V. H. Kuo, and J. R. Gyakum, Numerical simulations of a case of explosive marine cyclogenesis, Mon. Weather Rev., 111 1174-1188, 1983.

Atlas, R., Atmospheric observations and experiments to assess their 
usefulness in data assimilation, J. Meteorol. Soc. Jpn., 75, 111-130, 1997.

Atlas, R., and R. N. Hoffman, The use of satellite surface wind data to improve weather analysis and forecasting, in Satellites, Oceanography and Society, pp. 57-79, Elsevier, New York, 2000.

Atlas, R., E. Kalnay, and M. Halem, Impact of satellite temperature soundings and wind data on numerical weather prediction. $O p t$. Eng., 24, 341-346, 1985.

Baker, W. E., R. Atlas, E. Kalnay, M. Halem, R. M. Woiceshyn, S. Peteherych, and D. Edelmann, Large-scale analysis and forecast experiments with wind data from the Seasat-A scatterometer, $J$. Geophys. Res., 89, 4927-4936, 1984.

Bourassa, M. A., D. M. Legler, and J. J. O'Brien, NSCAT winds validation with research ship observations, Eas Trans. $A G U, 78(17)$, Spring Meet. Suppl., S76, 1997.

Bourassa, M. A., L. Zamudio, and J. J. O'Brien, Noninertial flow in NSCAT observations of Tehuantepec Winds, J. Geophys. Res., 104, $11,311-11,319,1999$.

Brown, R. A., and G. Levy, Ocean surface pressure fields from satellite-sensed winds, Mon. Weather Rev., 114, 2197-2206, 1986.

Brown, R: A, and L. Zeng, Estimating central pressures of oceanic midlatitude cyclones, J. Appl Meteorol., 33, 1088-1095, 1994.

Browning, K. A., and N. M. Roberts, Structure of a frontal cyclone, Q. J. R. Meteorol Soc., 120, 1535-1557, 1994.

Carlson, T. N., Airflow through midlatitude cyclones and the comma cloud pattern, Mon. Weather Rev., 108, 1498-1509, 1980.

Clarke, R. H, and G. D. Hess, On the relation between surface wind and pressure gradient, especially in the lower latitudes, $J$. Phys. Oceanozy., 9, 325-339, 1975.

Djuric, D., Weather Analysis, 304 pp., Prentice-Hall, Englewood Cliffs, N. J., 1994.

Duffy, D. G., and R. Atlas, The impact of Seasat-A scatterometer data on the numerical prediction of the Queen Elizabeth II storm, $J$. Geophys. Res., 91, 2241-2248, 1986.

Duffy, D., R. Atlas, T. Rasmond, E. Barker, and R. Rosenberg, The impact of Seasat scatterometer winds on the Navy's operational model, J. Geophys. Res., 89, 7238-7244, 1984.

Freilich, M., and R. S. Dunbar, A preliminary C-band scatterometer. model function for the ERS-1 AMI instrument, paper presented at First ERS-1 Symposium, European Space Agency, Cannes, France, 1992.

Freilich, M., and R. S. Dunbar, The accuracy of NSCAT 1 vector winds: Comparisons with National Data Buoy Center buoys, J. Geophys. Res., 104, 11,231-11,246, 1999.

Harlan, J., Jr., and J. J. O'Brien, Assimilation of scatterometer winds into surface pressure fields using a variational method, J. Geophys. Res., 91, 7816-7836, 1986.

Hoffman, R. N., A preliminary study of the impact of the ERS-1 C-band scatterometer wind data on the European Centre for Medium-Range Weather Forecasts global data assimilation system, $J$. Geophys. Res., 98, 10,233-10,244, 1993.

Hsu, C. S., and M. G. Wurtele, Construction of marine surface pressure fields from scatterometer winds, J. Geophys. Res., 36, 1249$1261,1997$.

Katsaros, K. B., J. M. Adams, and N. M. Mognard, Evolution of two oceanic extratropical cyclones as observed with the special sensor microwave imager and the Geosat and ERS-1 altimeters, J. Geophys. Res., 101, 6627-6639, 1996.

Levy, G., and R. A. Brown, Southern Hemisphere synoptic weather from a satellite scatterometer, Mon. Weather Rev., 119, 2803-2813, 1991.

Liu, W. T., W. Q. Tang, and P. S. Polito, NASA scatterometer provides global ocean-surface wind fields with more structures than numerical weather prediction, Geophys. Res. Lett., 25, 761-764, 1998.

Renka, R., Interpolation of data on the surface of a sphere, Oak Ridge Nath Lab. Rep. OLNR/CSD-108, Oak Ridge Natl. Lab., Oak Ridge, Tenn., 1982.

Saski, Y., Some basic formalisms in numerical variational analysis, Mon. Weather Rev., 108, 875-883, 1970.

Tomassini, M., D. LeMeur, and R. W. Sounders, Near-surface satellite wind observations of hurricanes and their impact on ECMWF model analyses and forecasts, Mon. Weather Rev., 126, 1274-1286, 1998.

Verschell, M. A., M. A. Bourassa, D. E. Weissman, and J. J. O'Brien, Model validation of the NASA scatterometer winds, $J$. Geophys. Res., 104, 11,359-11,373, 1999.

Zeng, L. X., and R. A. Brown, Scatterometer observations at high wind speeds, J. Appl. Meteorol., 37, 1412-1420, 1998.

M. A. Bourassa, James J. O'Brien, and D. F. Zierden, Center for Ocean-Atmospheric Prediction Studies, Florida State University, Tallahassee, FL 32306-2840. (zierden@coaps.fsu.edu)

(Received March 22, 1999; revised February 14, 2000; accepted March 20, 2000.) 